\title{
COMMENTS ON THE USE OF AERIAL PHOTOGRAPHS FOR FORESTRY PURPOSES IN THE UNITED STATES
}

\author{
By Stuart Molr, M.F. \\ Yale Forest School, Secretary Western Pine Association
}

$\mathrm{T}$

HE discussion in the last issue of the News Letter on the use of aerial photographs by foresters for purposes of type identification, the delineation of forest type boundaries, and the recognition of tree species, raised the most important question of the map scale of vertical photographs best suited to the job. There are many instances of foresters rejecting aerial photographs as useless because the scale of the photograph has been too small to make correct identification possible. This is due to a lack of appreciation of the limitations of map scale.

The failure of an aerial survey to serve the purpose for which it is intended can be very costly. A most important influence on the scale adopted for a survey is the amount of money available to make it. In this matter of expenditure false economy has frequently been practiced with the result that the photographs have not suited the purpose for which they were intended. It would be better to map a smaller area at a larger scale and have useable photographs than to extend the area mapped on a smaller scale with unsatisfactory results.

In the majority of cases for forestry work a mosaic map is not needed. Contact prints of a uniform scale which have ample stereoscopic over-lap are sufficient. A good stereoscope is an essential aid to correct interpretation. The question of scale is of paramount importance. Attempts made to map mountainous west coast areas at one inch equals one-half mile, have given unsatisfactory results, even for the accurate interpretation of type boundaries. The identification of tree species at this scale is out of the question. A scale of one inch equals 1,200 feet has proven satisfactory in some regions to determine general forest types, to study variation in tree height, crown spread, density of stand, and to distinguish different age types. Good results have been obtained with photographs flown at a scale of one inch equals 800 feet, and it was possible to identify mature tree species, and to spot trees attacked by insects.

In the Mississippi Valley, the United States Forest Service experience in using aerial photographs in connection with the survey of the forest of the alluvial bottom lands indicated that scales smaller than $1 / 12000$ should not be 
used. This scale would be found quite suitable for photographs to be used in connection with a program of land acquisition and protection. For purposes of timber estimating and careful type mapping, the writer's experience indicates that a scale of one inch equals 600 feet, or one inch equals 800 feet, produces better results. A most useful scale is one inch equals 660 feet.

The use of overlays or the transferring of type data from photographs to other maps is not at all necessary. It is much simpler to outline the types right onto the photograph, and this method is also more accurate.

It is always hazardous to quote prices of aerial surveys, because of the wide variation in the factors involved, but the following cost based on actual experience may serve in some measure as a guide. A survey made a few years ago in the Sierras of California covering seventy-five square miles at a scale of one inch equals 1,200 feet, cost five cents an acre. This survey included four sets of contact prints, and a rough mosaic map. Another survey in the coast range of California, covering sixty square miles at a scale of one inch equals one thousand feet, cost five cents per acre for contact prints only.

Prices in the southern United States are somewhat lower. The cost of making a survey of one hundred square miles, at a scale of one inch equals one thousand feet, requiring the delivery of contact prints only, will probably average about one cent an acre. If the area is under one hundred square miles, and the contact prints' scale one inch equals 600 feet, the cost might run as high as four and one-half cents an acre.

The question of using multilens photography and rectified photographs at a scale of one inch to the mile or even one-half inch to the mile, has been discussed, and the opinion expressed that for use in land classification and for rough drainage maps, they are excellent. For the detail of type mapping and for use in estimating they should not be considered, even though the cost might be only $6 / 10$ cents an acre. It is best economy to obtain photographs at a larger scale so as to be assured of dependable and satisfactory results.

\section{THE FORESTRY NEWS DIGEST}

$$
\text { Gives 1,500-Acre Forest to U.S. }
$$

The gift to the federal government of a 1,500-acre tract of land in northwest Massachusetts by Williams College, Willianstown, Mass., to be known as the Lawrence Hopkins Memorial Experimental Forest, is announced. The tract will be administered by the Forest Service as a branch of its Northeast Forest Experiment Station. The forest is in the extreme northwest corner of Massachusetts. 